\title{
Ganho de Peso Antes e Após os Sete Meses no Desenvolvimento e Características Quantitativas da Carcaça de Novilhos Nelore Abatidos aos Dois Anos
}

\author{
Fabiano Nunes Vaz ${ }^{1}$, João Restle ${ }^{2}$, Ricardo Zambarda Vaz ${ }^{3}$, Ivan Luiz Brondani ${ }^{4}$, João Teodoro \\ Pádua $^{5}$, Paulo Santana Pacheco ${ }^{6}$, Angélica Pereira dos Santos ${ }^{7}$
}

\begin{abstract}
RESUMO - O objetivo do trabalho foi estudar o desenvolvimento e as características de carcaça de novilhos Nelore abatidos aos dois anos de idade, classificados em quatro grupos conforme o ganho de peso médio diário (GMD) antes e após os sete meses de idade: alto-alto = novilhos com GMD $\geq 0,44 \mathrm{~kg}$ desde o nascimento até o abate, baixo-baixo = novilhos com GMD $<0,44 \mathrm{~kg}$ desde o nascimento até o abate, alto-baixo = novilhos com GMD $\geq 0,44 \mathrm{~kg}$ até os sete meses, e GMD $<0,44 \mathrm{~kg}$ dos sete meses ao abate, e baixo-alto = animais com GMD $<0,44 \mathrm{~kg}$ até os sete meses e GMD $\geq 0,44 \mathrm{~kg}$ dos sete meses ao abate. Aos sete meses, os animais que tiveram menor ganho de peso (baixo-alto e baixo-baixo) apresentaram, na média, $109 \mathrm{~kg}$ contra $154 \mathrm{~kg}$ dos alto-baixo e alto-alto. Os animais alto-alto e altobaixo apresentaram maior peso aos 18 meses em relação aos demais grupos, mas ao abate os novilhos alto-alto (396 kg) e alto-baixo (382 kg) foram superiores somente aos baixo-baixo (335 kg); o mesmo foi verificado com o peso de carcaça, que foi de 221, 207 e $182 \mathrm{~kg}$, citados na mesma ordem. A porcentagem de costilhar foi maior nos novilhos alto-alto (13,8\%) em relação aos baixo-alto (12,7\%) e baixo-baixo $(12,1 \%)$, mas a porcentagem de serrote foi menor nos alto-alto (48,4\%) do que nos baixo-baixo (50,2\%). As análises de contraste comparando o GMD antes e após os sete meses de idade mostraram que somente o GMD antes dos sete meses foi importante para características como peso aos 12 e 18 meses de idade, espessura de gordura subcutânea, porcentagem de costilhar, comprimento de carcaça e comprimento de perna. Ambos os efeitos, GMD antes e após os sete meses, influenciaram os pesos de abate e de carcaça, a porcentagem de serrote e o comprimento de braço.
\end{abstract}

Palavras-chave: acabamento, bezerros, Bos indicus, ganho compensatório, medidas da carcaça

\section{Pre and Post Seven Months Weight Gain on Development and Quantitative Carcass Characteristics of Nellore Steers Slaughtered at Two Years}

\begin{abstract}
The objective of the experiment was to study the development and carcass characteristics of Nellore steers, slaughtered at two years of age classified in four groups according to the average daily weight gain (ADG) pre and post seven months: high-high = steers with ADG $\geq .44 \mathrm{~kg}$ from birth to slaughter, low-low = steers with ADG $<.44 \mathrm{~kg}$ from birth to slaughter, high-low = steers with ADG $\geq .44 \mathrm{~kg}$ before seven months, and ADG $<.44 \mathrm{~kg}$ from seven months to slaughter, and low-high = animals with ADG $<.44 \mathrm{~kg}$ before seven months and ADG $\geq .44 \mathrm{~kg}$ from seven months to slaughter. At seven months, the animals with lower weight gain (low-high and low-low) showed, in average, $109 \mathrm{~kg}$ versus $154 \mathrm{~kg}$ for high-low and high-high steers. High-high and high-low animals showed higher live weight at 18 months than the other groups, but at slaughter high-high (396 kg) and high-low (382 kg) steers were only heavier than low-low (335 kg) steers, the same was verified with the carcass weight, wich was 221, 207 and $182 \mathrm{~kg}$, in the same order. Sidecut percentage was higher for high-high steers (13.8\%) than low-high (12.7\%) and low-low (12.1\%) steers, but sawcut percentage was lower for high-high (48.4\%) than low-low (50.2\%) steers. Contrast analysis comparing pre and post seven months ADG, showed that only pre seven months ADG effect was important for characteristics like weight at twelve and eighteen moths, subcutaneous fat thickness, sidecut percentage, carcass length and leg length. Both effects, ADG pre and post seven months, affected slaughter and carcass weight, sawcut percentage and arm length.
\end{abstract}

Key Words: Bos indicus, calves, carcass measurements, compensatory gain, fatness

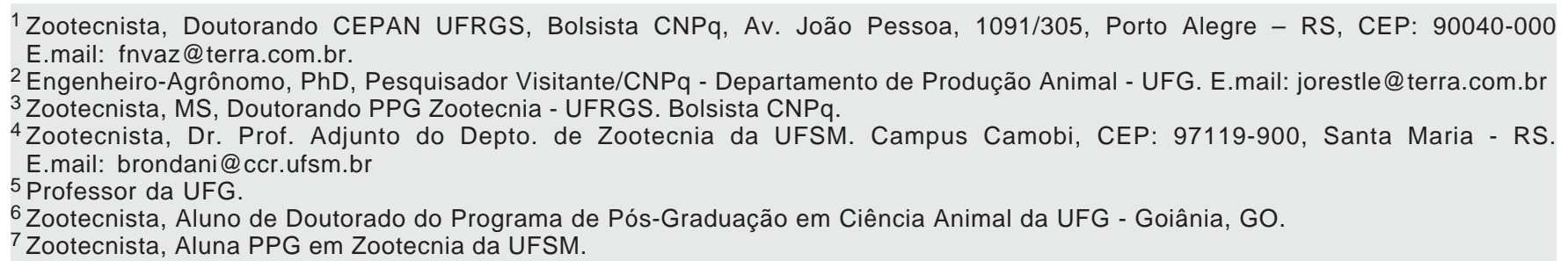




\section{Introdução}

Somente nos últimos anos o país tem percebido a importância da agropecuária nas exportações brasileiras; nesse aspecto, é atribuído ao setor de carnes o maior crescimento nos últimos anos. Entretanto, nos três maiores segmentos brasileiros produtores de carne, parece bem clara a diferença de qualidade e padronização das carnes de monogástricos e de bovinos. Alguns autores (Restle \& Vaz, 1998; 2002; Vaz et al., 1999) têm citado esse fato, juntamente com as barreiras sanitárias, como o maior empecilho ao crescimento da produção bovina de corte, que poderia ser mais procurada pelos mercados externo e interno.

As pesquisas brasileiras têm sido conduzidas no sentido de melhorar e estabelecer padrões de produtividade para a pecuária nacional. Nesse sentido, os trabalhos de melhoramento genético resultaram em significativas melhorias nos padrões de produtividade do Nelore, que é a raça de maior participação no rebanho brasileiro. Além disso, nota-se que os sistemas de produção que abatem animais aos dois anos de idade são boas alternativas, por não demandarem maiores volumes de recursos e oferecerem ao consumidor carne de boa qualidade (Vaz et al., 1999, 2000; Restle \& Vaz, 2002) e, mesmo que não sejam atingidos elevados peso de abate, é possível obter carcaças com bom acabamento (Harrison et al., 1978; Restle et al., 1997; Costa et al., 2002).

Cieslar \& Fleming (2003) alertam que, em bovinos, a restrição de crescimento abaixo dos níveis de mantença, seguida por um período de realimentação, aumenta a eficiência de ganho de peso dos animais. Bail et al. (2000) verificaram que a restrição alimentar qualitativa no período que antecedeu a terminação em confinamento resultou em aumento do ganho de peso, consumo e eficiência alimentar no período subseqüente. Muller \& Primo (1986) estabeleceram a importância do ganho de peso durante a recria dos novilhos, como determinante da idade de abate e, conseqüentemente, das características de carcaça. Com respeito ao crescimento antes dos sete meses, Restle et al. (1999a) salientam que o peso nessa idade é fator determinante nos sistemas de produção, indicando que sistemas mais intensivos requerem que os bezerros atinjam altos ganhos de peso durante a fase de aleitamento, para que se viabilize o acasalamento das fêmeas aos dois anos e abate dos machos aos 14 meses de idade.

Por outro lado, Restle et al. (1999c) verificaram que, embora o crescimento possa ser menor dos três aos sete meses de idade, é possível recuperar esse menor desenvolvimento até os 24 meses de idade, resultando em carcaça e carne com caraterísticas semelhantes. Arboitte et al. (2004) comentam que nos trabalhos de pesquisa nos quais os animais são abatidos aos dois anos de idade, ocorre ganho de peso compensatório em função de restrições de crescimento, as quais precisam ser melhor estudadas em condições brasileiras.

O objetivo deste trabalho foi estudar o efeito de diferentes ganhos de peso, em duas fases distintas do processo de criação de novilhos da raça Nelore, sobre os pesos em diferentes idades e o desenvolvimento da carcaça, em animais abatidos aos dois anos de idade.

\section{Material e Métodos}

O experimento foi conduzido no Setor de Bovinocultura de Corte e no Laboratório de Carnes do Departamento de Zootecnia da Universidade Federal de Santa Maria - RS (UFSM). Os dados analisados referem-se a 96 novilhos Nelore oriundos do mesmo rebanho e mantidos sob as mesmas condições de manejo e alimentação, sendo que o desmame e a castração ocorreram aos sete meses de idade.

Os animais foram manejados ao pé da vaca em campo nativo até o desmame aos sete meses de idade e, posteriormente, encaminhados para pastagem cultivada formada por aveia preta (Avena strigosa L.) + azevém (Lolium multiflorum L.), retornando para campo nativo no segundo verão, sendo terminados no segundo inverno, pastejando a mesma consorciação de forrageiras usada no primeiro inverno (aveia preta + azevém).

Foram estudados quatro grupos: alto-alto $=$ novilhos com GMD $>0,44 \mathrm{~kg}$ desde o nascimento até o abate; baixo-baixo = novilhos com GMD $<0,44 \mathrm{~kg}$ desde o nascimento até o abate; alto-baixo $=$ novilhos com GMD $>0,44 \mathrm{~kg}$ até os sete meses e GMD $<0,44 \mathrm{~kg}$ dos sete meses ao abate; e baixo-alto = animais com GMD $<0,44 \mathrm{~kg}$ até os sete meses e GMD $>0,44$ kg dos sete meses ao abate (Tabela 1 ).

Os animais foram abatidos em frigorífico comercial e o peso de abate dos animais foi tomado antes do embarque para o estabelecimento, observando-se jejum de sólidos de 12 horas. O abate seguiu o fluxo normal do frigorífico; em seguida, as carcaças foram lavadas e identificadas antes de entrar para a câmara de resfriamento. Decorridas 24 horas de resfriamento $\left(-1^{\circ} \mathrm{C}\right)$, foi medido o peso de carcaça fria. 
Na meia-carcaça direita, seguindo os métodos descritos por Muller (1987), foi realizada a avaliação subjetiva da maturidade fisiológica da carcaça, observando-se o grau de ossificação das apófises espinhosas das vértebras torácicas e fusionamento das vértebras sacrais, em que valores mais baixos da escala de 15 pontos indicam maturidade fisiológica mais avançada. O comprimento de carcaça foi medido desde o bordo cranial, na porção média da primeira costela até o bordo cranial do osso púbis. O comprimento de perna também foi medido deste mesmo último ponto até a articulação tíbio-tarsiana.

O braço teve seu comprimento medido desde a tuberosidade do olécrano até a extremidade distal do úmero e seu perímetro medido na porção média do úmero, envolvendo os músculos que recobrem a região. A espessura de coxão foi medida com compasso - uma das pontas foi fixada na parte mais externa do coxão de dentro e a outra, na face externa da perna, perpendicular ao comprimento do corte serrote.

A meia-carcaça esquerda foi dividida nos cortes dianteiro, costilhar e serrote, que foram pesados para cálculo da porcentagem destes em relação ao peso da carcaça fria.

O delineamento experimental utilizado foi o inteiramente casualizado, com número diferente de repetições. As características dependentes foram interpretadas por análise de variância e teste F (5\%), seguido do teste Tukey (5\%) para comparação das médias.

As comparações referentes aos efeitos dos ganhos de peso antes e após os sete meses foram realizadas por meio de análises de contrastes, realizando-se as seguintes comparações: 1) Alto-alto + alto-baixo contra baixo-alto + baixo-baixo; 2) Alto-alto + baixoalto contra alto-baixo + baixo-baixo, sendo que o “contraste 1" permite estimativa do efeito do ganho de peso antes dos sete meses e o "contraste 2", a estimativa do efeito do ganho de peso após os sete meses sobre as características dependentes estudadas.

\section{Resultados e Discussão}

Na Tabela 2, são apresentadas as médias referentes ao peso dos animais ao nascer, aos sete, 12, 18 e 24 meses de idade, bem como o ganho de peso nos diferentes intervalos. Na comparação individual dos grupos, verifica-se que não houve diferença entre os animais no peso ao nascer, mas aos sete meses os animais alto-alto e alto-baixo foram mais pesados que os baixo-alto e baixo-baixo. Aos 12 meses, não houve diferença entre os novilhos alto-baixo e baixoalto, mas aos 18 meses os animais alto-alto e altobaixo voltaram a ser mais pesados $(\mathrm{P}<0,05)$ que os baixo-alto e baixo-baixo.

Na comparação entre os novilhos alto-baixo e baixo-alto, verificou-se que os animais do último grupo apresentavam $56 \mathrm{~kg}$ a menos $(\mathrm{P}<0,05)$ aos sete meses, resultando em ganho compensatório dos animais baixoalto dos 7 aos 12 meses (70 kg no período ou 0,47 kg por dia), comparados com novilhos alto-baixo ( $35 \mathrm{~kg}$ ou $0,23 \mathrm{~kg}$ por dia). Esse ganho de peso fez com que não houvesse diferença $(\mathrm{P}>0,05)$ entre baixo-alto e altobaixo aos 12 meses, mas aos 18 meses de idade os animais alto-alto e alto-baixo voltaram a ser mais pesados $(\mathrm{P}<0,05)$ que os baixo-alto e baixo-baixo, mostrando que houve, possivelmente, ganho de peso compensatório dos novilhos baixo-alto logo após os sete meses de idade, o qual cessou logo em seguida, conforme mostra a Figura 1.

Apesar de os novilhos alto-baixo serem os animais que apresentavam maior ganho de peso até o desmame,

Tabela 1 - Classificação dos grupos conforme o ganho de peso diário nas diferentes fases da vida

Table 1 - Classification of the groups studied, according to daily weight gain in the different live phasis

\begin{tabular}{lcccc}
\hline $\begin{array}{l}\text { Ganho de peso diário } \\
\text { Daily weight gain }\end{array}$ & \multicolumn{4}{c}{$\begin{array}{c}\text { Grupo pesquisado } \\
\text { Studied group }\end{array}$} \\
\cline { 2 - 5 } & Alto-alto & Alto-baixo & Baixo-alto & Baixo-baixo \\
\hline $\begin{array}{l}\text { Do nascimento aos sete meses, } \mathrm{kg} \\
\text { From birth to seven months, } \mathrm{kg}\end{array}$ & $\geq 0,44$ & $\geq 0,44$ & $<0,44$ & $<0,44$ \\
$\begin{array}{l}\text { Dos sete meses ao abate, } \mathrm{kg} \\
\text { From seven months to slaughter, } \mathrm{kg}\end{array}$ & $\geq 0,44$ & $<0,44$ & $\geq 0,44$ & $<0,44$ \\
$\begin{array}{l}\text { Número de animais por grupo } \\
\text { Number of animals per group }\end{array}$ & 11 & 26 & 15 & 44 \\
\hline
\end{tabular}

R. Bras. Zootec., v.33, n.4, p.1029-1038, 2004 


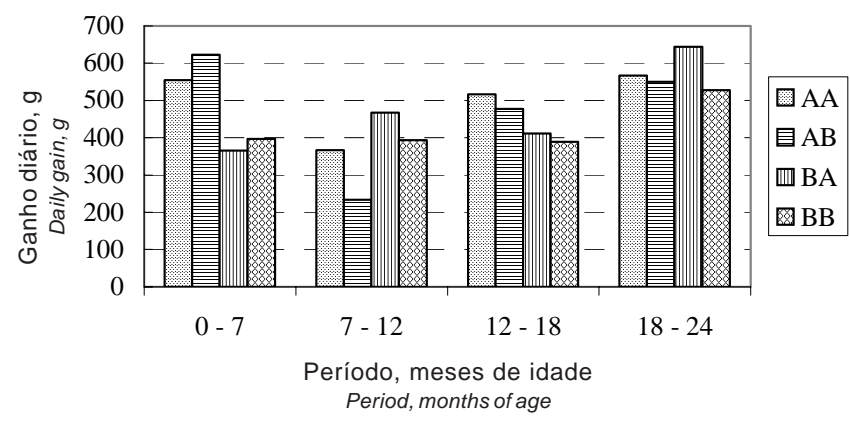

Figura 1 - Ganho médio diário dos novilhos em diferentes fases.

Figure 1 - Average daily gain of steers in different phases.

logo em seguida, os mesmos mostraram o menor ganho de peso dos quatro grupos, em todos os períodos, quando se calculou o ganho dos 7 aos 12 meses de idade. Esses resultados indicam haver maior efeito adverso da desmama no lote que apresentava, até então, o melhor desempenho, resultados explicados por Pascoal et al. (2000) como resposta negativa apresentada por bezerros jovens filhos de vacas de melhor produção leiteira, em função da maior dependência do leite em seu desenvolvimento até a desmama.

A Figura 1 também ilustra que o período dos 7 aos 12 meses de idade foi o que apresentou menores ganhos de peso dos animais; após o desmame, à medida que aumenta a idade dos animais, cresce também o ganho de peso, sendo na média de 485, 365, 449 e 572 g por dia, respectivamente, para os períodos do nascimento ao desmame (sete meses), dos 7 aos 12, dos 12 aos 18 e dos 18 aos 24 meses de idade.

Aos 18 meses de idade, houve diferença de peso $(\mathrm{P}<0,05)$ entre alto-baixo em relação aos baixo-alto e baixo-baixo. No entanto, o peso de abate aos 24 meses foi similar entre alto-baixo e baixo-alto e entre baixo-alto e baixo-baixo, reflexo do maior ganho de peso dos animais baixo-alto na fase de terminação (18 aos 24 meses).

A Figura 1 mostra que dos 7 aos 12 meses, os animais com crescimento mais lento na fase anterior apresentaram desempenho superior, o que, segundo Di Marco (1994) e Lawrence \& Fowler (1997),

Tabela 2 - Médias das características relacionadas ao peso vivo em diferentes idades, para cada grupo de novilhos e contrastes entre alto-alto $(A A)+$ alto-baixo $(A B)$ contra baixo-alto $(B A)+$ baixo-baixo (BB) (PRE) e entre AA + BA contra AB + BB (POS)

Table 2 - Means for growth related characteristics in different ages for each steers group and contrasts between high-high $(A A)+$ high-low $(A B)$ versus low-high $(B A)+$ low-low (BB) (PRE) and between $A A+B A$ versus $A B+B B(P O S)$

\begin{tabular}{|c|c|c|c|c|c|c|}
\hline \multirow[t]{2}{*}{$\begin{array}{l}\text { Característica } \\
\text { Characteristic }\end{array}$} & \multicolumn{4}{|c|}{$\begin{array}{l}\text { Grupo pesquisado } \\
\text { Studied group }\end{array}$} & \multicolumn{2}{|c|}{$\begin{array}{l}\text { Contraste } \\
\text { Contrast }\end{array}$} \\
\hline & AA & $\mathrm{AB}$ & BA & $\mathrm{BB}$ & PRE & POS \\
\hline $\begin{array}{l}\text { Peso ao nascer, kg } \\
\text { Birth weight, } \mathrm{kg}\end{array}$ & 29,6 & 31,2 & 29,3 & 27,6 & NS & NS \\
\hline $\begin{array}{l}\text { Ganho de peso dos } 0 \text { aos } 12 \text { meses, } \mathrm{kg} \\
\text { Weight gain from } 0 \text { to } 12 \text { months, } \mathrm{kg}\end{array}$ & 116 & 131 & 77 & 83 & - & - \\
\hline $\begin{array}{l}\text { Peso aos sete meses, kg } \\
\text { Seven months weight, } \mathrm{kg}\end{array}$ & $146 \mathrm{a}^{+}$ & 162 a & $106 \mathrm{~b}$ & $111 \mathrm{~b}$ & $* *$ & NS \\
\hline $\begin{array}{l}\text { Ganho de peso dos } 7 \text { aos } 12 \text { meses, kg } \\
\text { Weight gain from } 7 \text { to } 12 \text { months, } \mathrm{kg}\end{array}$ & 55 & 35 & 70 & 59 & - & - \\
\hline $\begin{array}{l}\text { Peso aos doze meses, } \mathrm{kg} \\
\text { Twelve months weight, } \mathrm{kg}\end{array}$ & $201 \mathrm{a}$ & $197 \mathrm{ab}$ & 176 bc & $170 \mathrm{c}$ & $* *$ & NS \\
\hline $\begin{array}{l}\text { Ganho de peso dos } 12 \text { aos } 18 \text { meses, kg } \\
\text { Weight gain from } 12 \text { to } 18 \text { months, kg }\end{array}$ & 93 & 86 & 74 & 70 & - & - \\
\hline $\begin{array}{l}\text { Peso aos dezoito meses, } \mathrm{kg} \\
\text { Eighteen months weight, } \mathrm{kg}\end{array}$ & $294 \mathrm{a}$ & $283 a$ & $250 \mathrm{~b}$ & $240 b$ & $* *$ & NS \\
\hline $\begin{array}{l}\text { Ganho de peso dos } 18 \text { aos } 24 \text { meses, kg } \\
\text { Weight gain from } 12 \text { to } 18 \text { months, kg }\end{array}$ & 102 & 99 & 116 & 95 & - & - \\
\hline $\begin{array}{l}\text { Peso de abate ( } 24 \text { meses), kg } \\
\text { Slaughter weight ( } 24 \text { months), } k g \\
\end{array}$ & $396 a$ & 382 a & 366 ab & $335 b$ & $* *$ & $* *$ \\
\hline
\end{tabular}

+ a, b na linha, na comparação entre todos os grupos, são diferentes pelo teste Tukey a 5\%.

$+a, b$ in the line, in the comparison among all groups, are different by Tukey test at $5 \%$.

$\star * * 0,01$

\section{R. Bras. Zootec., v.33, n.4, p.1029-1038, 2004}


caracteriza crescimento compensatório dos animais. Cieslar \& Fleming (2003) relatam que as respostas hormonais para restrição e realimentação parecem induzir a incrementos das taxas de ganho de peso, uso mais eficiente dos nutrientes e maior grau de deposição de proteína.

Na Tabela 2, observa-se que dos 12 aos 18 meses, os novilhos baixo-alto voltaram a ganhar menos peso que os alto-baixo, sendo $33 \mathrm{~kg}$ mais leves ao sobreano e, embora tenham ganhado $17 \mathrm{~kg}$ a mais dos 18 aos 24 meses de idade, pesaram $366 \mathrm{~kg}$ contra $382 \mathrm{~kg}$ dos alto-baixo ao abate $(\mathrm{P}<0,05)$. Esses resultados mostram que, após os sete meses, os novilhos baixo-alto mostraram crescimento compensatório. Yambayamba et al. (1996) relatam que a compensação de desenvolvimento subseqüente a um período de restrição de crescimento pode ser parcial, total ou mesmo inexistente, mas sempre é mais pronunciada no momento imediato à restrição, desde que seja oferecido aos animais um período de maior oferta de nutrientes.

As análises de contraste revelaram que os ganhos de peso antes dos sete meses de idade tiveram efeito significativo $(\mathrm{P}<0,01)$ nos pesos aos 12 , 18 e 24 meses de idade, enquanto o ganho de peso após os sete meses apresentou efeito significativo $(\mathrm{P}<0,01)$ somente sobre o peso ao abate. Observou-se também que os animais dos grupos baixo-alto e baixo-baixo apresentaram peso semelhante ao desmame e se desenvolveram de maneira similar. Assim, não existiu diferença significativa entre esses grupos em todas as pesagens realizadas até o abate, evidenciando que o ganho de peso antes do desmame foi fator determinante para o desenvolvimento dos animais até o abate. Restle et al. (1999b) verificaram, em bezerros Braford, que a diferença apresentada no peso aos sete meses, entre animais desmamados em diferentes idades (72 ou 210 dias), se manteve até o abate aos 14 meses, mostrando que o crescimento dos animais mais leves não foi afetado no período anterior aos sete meses, mas que houve maior crescimento dos animais que receberam melhores condições.

O peso de carcaça foi maior nos animais alto-alto em relação aos baixo-alto e baixo-baixo, e dos altobaixo em relação aos baixo-baixo (Tabela 3). Assim como aconteceu com o peso aos 24 meses, o peso de carcaça também foi afetado pelos ganhos de peso antes e após os sete meses de idade $(\mathrm{P}<0,01)$.

Verifica-se peso médio de $214 \mathrm{~kg}$ de carcaça para os animais com alto ganho de peso antes dos sete meses de idade e de $191 \mathrm{~kg}$ para os animais com ganho de peso inferior a 0,44 kg antes do desmame. Restle et al. (1999c) desmamaram bezerros aos três e sete meses pós-parto, abatendo-os quando completaram 24 meses de idade, observando que, embora os animais desmamados mais cedo tivessem apresentado menor peso aos sete meses de idade, o maior ganho

Tabela 3 - Médias para cada grupo de novilhos e contrastes entre alto-alto $(A A)+$ alto-baixo ( $A B)$ contra baixo-alto (BA) + baixo-baixo (BB) (PRE) e entre AA + BA contra AB + BB (POS), das características peso de carcaça, rendimento de carcaça e espessura de gordura subcutânea (EGS)

Table 3 - Means for each steers group and contrasts between high-high $(A A)+$ high-low $(A B)$ versus low-high $(B A)$ + low-low (BB) (PRE) and between $A A+B A$ versus $A B+B B(P O S)$, of carcass weight, dressing percentage and subcutaneous fat thickness (SFT) characteristics

\begin{tabular}{|c|c|c|c|c|c|c|}
\hline \multirow[t]{2}{*}{$\begin{array}{l}\text { Característica } \\
\text { Characteristic }\end{array}$} & \multicolumn{4}{|c|}{$\begin{array}{l}\text { Grupo pesquisado } \\
\text { Studied group }\end{array}$} & \multicolumn{2}{|c|}{$\begin{array}{c}\text { Contraste } \\
\text { Contrast }\end{array}$} \\
\hline & AA & $\mathrm{AB}$ & BA & $\mathrm{BB}$ & PRE & POS \\
\hline $\begin{array}{l}\text { Peso de carcaça fria, } \mathrm{kg} \\
\text { Cold carcass weight, } \mathrm{kg}\end{array}$ & $221 \mathrm{a}^{+}$ & $207 a b$ & 199 bc & $182 \mathrm{c}$ & $* *$ & $* *$ \\
\hline $\begin{array}{l}\text { Rendimento de carcaça fria, } \mathrm{kg} \\
\text { Cold dressing percentage, } \mathrm{kg}\end{array}$ & 55,6 & 53,9 & 54,5 & 53,9 & NS & NS \\
\hline $\begin{array}{l}\text { Maturidade fisiológica, pontos } \\
\text { Physiologic maturity, points }\end{array}$ & 12,8 & 13,7 & 12,7 & 13,4 & NS & NS \\
\hline $\begin{array}{l}\text { EGS, mm } \\
\text { SFT, } \mathrm{mm}\end{array}$ & 4,18 & 3,59 & 3,63 & 3,09 & $*$ & NS \\
\hline $\begin{array}{l}\text { EGS, mm/100 kg de carcaça } \\
S F T, m m / 100 \mathrm{~kg} \text { of carcass }\end{array}$ & 1,88 & 1,73 & 1,84 & 1,67 & NS & NS \\
\hline
\end{tabular}

+ a, b na linha, na comparação entre todos os grupos, são diferentes pelo teste Tukey a $5 \%$.
$+a, b$ in the line, in the comparision among all groups, are different by Tukey test at $5 \%$.

${ }^{*} \mathrm{P}<0,05 \mathrm{e}{ }^{* *} \mathrm{P}<0,01\left({ }^{*} P<.05\right.$ and $\left.{ }^{* *} P<.01\right)$.

R. Bras. Zootec., v.33, n.4, p.1029-1038, 2004 
durante as fases de recria e terminação fez com que os animais não diferissem no peso de carcaças quente e fria dos animais desmamados mais velhos.

O rendimento de carcaça fria não diferiu entre os quatro grupos de novilhos ( $\mathrm{P}>0,05)$. Também na análise de contrastes não foi verificado efeito dos ganhos de peso $(\mathrm{P}>0,05)$ sobre esta característica. Estudando a restrição alimentar durante a terminação, Thiago et al. (1998) verificaram que o rendimento de carcaça se manteve inalterado nos níveis de restrição de 7,5 (54,8\%) e $15 \%$ do consumo ad libitum (54,7\%), em animais mestiços, e nos níveis de 0 (58,4\%), 7,5 (56,5\%) e 15\% (56,5\%) de restrição, em animais Nelore. Trenkle et al. (1978) observaram que animais sob restrição alimentar, para diminuir a velocidade de crescimento, tiveram rendimento de carcaça similar aos novilhos alimentados ad libitum, quando o peso de abate foi fixado em 360 ou $500 \mathrm{~kg}$. Aberle et al. (1981) reduziram a energia na dieta de bovinos em terminação em diferentes períodos: alta energia por 210 dias, baixa energia por 153 dias + alta energia por 70 dias e baixa energia por 230 dias, observando decréscimo no rendimento de carcaça, à medida que diminuia o nível energético na ração.

Restle et al. (1999c) observaram que bezerros com menor peso vivo aos sete meses de idade (desmame aos três meses pós-parto) mostraram rendimento de carcaça quente de $53,3 \%$, contra $52,2 \%$ dos animais mais pesados aos sete meses (desmamados aos sete meses). Barber et al. (1981) concluíram que as variações no rendimento de carcaça de animais contemporâneos e da mesma raça são dependentes do grau de acabamento no momento de abate.

Verifica-se que a espessura de gordura não diferiu entre os grupos de novilhos $(\mathrm{P}>0,05)$. Ao ajustar a espessura de gordura para o peso de carcaça fria dos animais, verifica-se novamente similaridade entre os grupos. No presente trabalho, a espessura de gordura não diferiu entre os tratamentos, embora a análise de contrastes tenha mostrado efeito significativo do ganho de peso pré-desmame sobre essa característica (Tabela 3).

Conforme vários autores (Muller, 1987; Di Marco, 1994; Restle et al., 1997; Vaz, 1999), animais que atingem maiores ganhos de peso tendem a apresentar carcaças com maior grau de acabamento. Durante a terminação de animais de dois anos em confinamento, Thiago et al. (1998) observaram que, em animais mestiços, a restrição alimentar de 7,5\% resultou em ganho de peso diário maior ( $1,77 \mathrm{~kg})$ e maior espessura de gordura $(3,7 \mathrm{~mm})$ que a restrição de $15 \%$ do consumo ad libitum (1,52 kg e 2,5 mm).

Trabalhando com a raça Belgian Blue, Hornick et al. (1998) escrevem que animais que sofrem períodos de restrição alimentar tendem a desenvolver maior quantidade de gordura externa e menores quantidades de gordura intra-muscular. Hogg (1991) descreve que, durante a fase de menor crescimento ou mesmo sob restrição alimentar, a gordura externa é a primeira a ser utilizada, seguida da gordura interna, sendo que no processo de aceleração do crescimento subseqüente o processo é inverso.

Bowling et al. (1977) alertam que o acúmulo de gordura na carcaça é fator preponderante na qualidade e maciez da carne de novilhos. Trenkle et al. (1978) concluíram que a deposição de gordura separável na carcaça é influenciada pela idade e pelo peso dos animais, pois animais abatidos aos $360 \mathrm{~kg}$ apresentaram quantidade de gordura similar na carcaça, comparando-se animais que sofreram restrição alimentar e animais alimentados ad libitum.

Estudando o marmoreio da carne de animais Angus e Pardo Suíço, Marshall et al. (1987) observaram efeito da produção de leite da mãe sobre a deposição de marmoreio na carne de novilhos quando foram abatidos.

Constam na Tabela 4 os resultados referentes ao desenvolvimento da carcaça, porcentagem e peso dos cortes comerciais. Observa-se que os animais alto-alto, alto-baixo e baixo-alto foram superiores aos novilhos baixo-baixo no comprimento de carcaça, de perna e de braço $(\mathrm{P}<0,05)$, sendo que a análise de contrastes revela efeito altamente significativo $(\mathrm{P}<0,01)$ do ganho de peso anterior aos sete meses de idade sobre estas três características. Restle et al. (1999c) observaram que animais mais leves aos sete meses apresentaram menor comprimento de carcaça aos 24 meses de idade. As características espessura de coxão e perímetro de braço foram similares entre os grupos e não foram afetadas $(\mathrm{P}>0,05)$ pelos ganhos de peso anterior ou posterior aos sete meses de idade.

Com relação aos cortes comerciais da carcaça, observa-se que a porcentagem de costilhar foi maior nos novilhos alto-alto em relação àqueles que tiveram menor desenvolvimento quando bezerros, fato comprovado pelos contrastes, que mostram efeito altamente significativo do ganho de peso antes dos sete meses sobre essa característica. A porcentagem de serrote foi maior nos animais baixo-baixo em relação 
aos novilhos alto-alto, sendo que os animais altobaixo e baixo-alto não diferiram dos demais grupos.

Os contrastes mostraram efeito tanto do GMD antes como após os sete meses sobre a porcentagem de serrote na carcaça. Quando as características avaliadas passaram a ser o peso dos cortes na carcaça, verificaram-se efeitos altamente significativos do ganho antes e após os sete meses, observando-se, na comparação individual entre os grupos, que os animais altoalto, embora apresentem menor porcentagem de corte serrote na carcaça, produzem maior peso desse corte que os novilhos baixo-alto e baixo-baixo.

Olson et al. (1978) relatam que o ganho de peso compensatório após o desmame elimina as diferenças existentes na fase de aleitamento, fazendo com que as características de peso e desenvolvimento da carcaça não difiram entre si, em animais abatidos com idade jovem. Vaz \& Restle (2003) observaram que a porcentagem de costilhar foi afetada pelo ganho de peso pré e pós-desmame, salientando a correlação existente entre porcentagem de costilhar e espessura de gordura subcutânea.

Os coeficientes de correlação entre as características estudadas são mostrados na Tabela 5. A espessura de gordura esteve correlacionada $(\mathrm{P}<0,01)$ com a porcentagem de costilhar, porém em valor inferior $(r=0,36)$ ao citado por Restle et al. (2001), em novilhas mestiças 1/4 Nelore 3/4 Charolês, $r=0,72$. No entanto, esses autores citam que a correlação não existiu $(r=-0,02)$, quando o genótipo de novilhas estudado foi o Charolês puro. A correlação entre porcentagem de costilhar e espessura de gordura explica-se pelo fato de a espessura de gordura ser medida no costilhar e, provavelmente, em animais Nelore puros ou mestiços Nelore, da mesma idade, o peso de costilhar (e, por conseguinte, a participação

Tabela 4 - Médias para cada grupo de novilhos e contrastes entre alto-alto $(A A)+$ alto-baixo $(A B)$ contra baixo-alto (BA) + baixo-baixo (BB) (PRE) e entre $A A+B A$ contra AB + BB (POS), das características de medidas de desenvolvimento na carcaça e cortes comerciais da carcaça

Table 4 - Means for each steers group and contrasts between high-high $(A A)+$ high-low $(A B)$ versus low-high $(B A)+$ low-low (BB) (PRE) and between $A A+B A$ versus $A B+B B(P O S)$, of the carcass development measures and commercial cuts characteristics

\begin{tabular}{|c|c|c|c|c|c|c|}
\hline \multirow[t]{2}{*}{$\begin{array}{l}\text { Característica } \\
\text { Characteristic }\end{array}$} & \multicolumn{4}{|c|}{$\begin{array}{l}\text { Grupo pesquisado } \\
\text { Studied group }\end{array}$} & \multicolumn{2}{|c|}{$\begin{array}{c}\text { Contraste } \\
\text { Contrast }\end{array}$} \\
\hline & AA & $\mathrm{AB}$ & BA & $\mathrm{BB}$ & PRE & $\mathrm{POS}$ \\
\hline $\begin{array}{l}\text { Comprimento de carcaça, cm } \\
\text { Carcass length, } \mathrm{cm}\end{array}$ & $118 \mathrm{a}^{+}$ & $117 \mathrm{a}$ & $117 \mathrm{a}$ & $113 \mathrm{~b}$ & $* *$ & NS \\
\hline $\begin{array}{l}\text { Comprimento de perna, } \mathrm{cm} \\
\text { Leg length, } \mathrm{cm}\end{array}$ & 74,6 a & 73,9 a & 73,8 a & $70,7 \mathrm{~b}$ & $* *$ & NS \\
\hline $\begin{array}{l}\text { Comprimento de braço, } \mathrm{cm} \\
\text { Arm length, } \mathrm{cm}\end{array}$ & $41,9 \mathrm{a}$ & $41,5 \mathrm{a}$ & $41,2 \mathrm{a}$ & $38,9 \mathrm{~b}$ & $* *$ & $*$ \\
\hline $\begin{array}{l}\text { Espessura de coxão, cm } \\
\text { Cushion thickness, } \mathrm{cm}\end{array}$ & 24,3 & 23,4 & 23,8 & 22,9 & NS & NS \\
\hline $\begin{array}{l}\text { Perímetro de braço, } \mathrm{cm} \\
\text { Arm perimeter, } \mathrm{cm}\end{array}$ & 33,4 & 33,2 & 34,0 & 32,4 & NS & NS \\
\hline $\begin{array}{l}\text { Dianteiro, \% } \\
\text { Forequarter, \% }\end{array}$ & 37,8 & 37,6 & 38,5 & 37,7 & NS & NS \\
\hline $\begin{array}{l}\text { Costilhar, \% } \\
\text { Sidecut, \% }\end{array}$ & $13,8 \mathrm{a}$ & $12,9 \mathrm{ab}$ & $12,7 \mathrm{~b}$ & $12,1 \mathrm{~b}$ & $* *$ & NS \\
\hline $\begin{array}{l}\text { Serrote, \% } \\
\text { Sawcut, \% }\end{array}$ & $48,4 \mathrm{~b}$ & 49,6ab & $48,8 \mathrm{ab}$ & $50,2 \mathrm{a}$ & $*$ & $*$ \\
\hline $\begin{array}{l}\text { Dianteiro, } \mathrm{kg} \\
\text { Forequarter, } \mathrm{kg}\end{array}$ & 83,5 a & 78,0 a & $77,2 \mathrm{a}$ & $68,8 b$ & $* *$ & $* *$ \\
\hline $\begin{array}{l}\text { Costilhar, kg } \\
\text { Sidecut, } \mathrm{kg}\end{array}$ & 30,5 a & $26,7 \mathrm{~b}$ & 25,5 bc & $22,1 \mathrm{c}$ & $* *$ & $* *$ \\
\hline $\begin{array}{l}\text { Serrote, kg } \\
\text { Sawcut, kg }\end{array}$ & 106,8 a & $102,8 \mathrm{ab}$ & 97,9 bc & $91,2 \mathrm{c}$ & $* *$ & $* *$ \\
\hline
\end{tabular}

${ }^{+}$a, b na linha, na comparação entre todos os grupos, são diferentes pelo teste Tukey a 5\%.

$+a, b$ in the line, in the comparision among all groups, are different by Tukey test at $5 \%$.

${ }^{*} \mathrm{P}<0,05$ e ${ }^{* *} \mathrm{P}<0,01\left({ }^{*} P<.05\right.$ and $\left.{ }^{* *} P<.01\right)$. 
percentual do corte na meia-carcaça) aumenta com o incremento da deposição de gordura.

Observa-se correlação positiva e altamente significativa $(\mathrm{P}<0,01)$ entre peso ao nascer e todas as características relacionadas ao peso dos 7 aos 24 meses, assim como ao peso de carcaça, sendo de 0,46; 0,29; 0,36 ; 0,35 e 0,31 os coeficientes de correlação, respectivamente, para peso aos 7, 12, 18 e 24 meses e peso de carcaça. Além dessas características, o peso ao nascer esteve relacionado somente com o comprimento de carcaça dos animais $(\mathrm{r}=0,30 ; \mathrm{P}<0,01)$.

Com relação ao rendimento de carcaça fria, verifica-se que o mesmo esteve correlacionado positivamente com o peso de carcaça $(r=0,40 ; \mathrm{P}<0,01)$ e com a porcentagem de dianteiro $(r=0,26 ; P<0,05)$. Em animais terminados com 24 meses, Restle et al. (1999c) observaram que a correlação entre rendimento de carcaça e peso de carcaça foi de 0,36 , quando o desmame ocorreu aos 210 dias de idade, e de 0,62 , quando o desmame foi aos 90 dias de idade. No mesmo trabalho, Restle et al. (1999c) comentam que existe correlação entre rendimento de carcaça e espessura de coxão, quando o desmame ocorre aos três meses $(0,45)$ e o bezerro apresenta baixo

Tabela 5 - Coeficientes de correlação de Pearson acima da diagonal entre as variáveis peso ao nascer $(P N)$, peso aos 7 (P7), aos 12 (P12) e aos 18 meses (P18), peso de abate (PA), peso de carcaça fria $(P F)$, rendimento de carcaça fria $(R C)$, maturidade fisiológica (MF), espessura de gordura $(E G)$, comprimento de carcaça $(C C)$ e de perna (CP), espessura de coxão (EC), porcentagem de traseiro especial (PT), de dianteiro (PD) e de costilhar (PC) e nível de significância, abaixo da diagonal

Table 5 - Pearson correlation coeficients above diagonal among the variables birth weight (BW), weight at seven (W7), at twelve (W12) and at eighteen months (W18), slaughter weight (SW), cold carcass weight (CW), cold dressing percentage (DP), phisyologic maturity (PM), fat thickness (FT), carcass $(C L)$ and leg length $(L L)$, cushion thickness (CT), sawcut (SA), forequarter (FO) and sidecut percentages (SI) and significance level under diagonal

\begin{tabular}{|c|c|c|c|c|c|c|c|c|c|c|c|c|c|c|c|}
\hline & $\begin{array}{l}\text { PN } \\
B W\end{array}$ & $\begin{array}{l}\text { P7 } \\
\text { W7 }\end{array}$ & $\begin{array}{l}\text { P12 } \\
\text { W12 }\end{array}$ & $\begin{array}{l}\text { P18 } \\
\text { W18 }\end{array}$ & $\begin{array}{l}\text { PA } \\
\text { SW }\end{array}$ & $\begin{array}{l}\mathrm{PF} \\
\mathrm{CW}\end{array}$ & $\begin{array}{l}\mathrm{RC} \\
D P\end{array}$ & $\begin{array}{l}\text { MF } \\
P M\end{array}$ & $\begin{array}{l}\text { EG } \\
F T\end{array}$ & $\begin{array}{l}C C \\
C L\end{array}$ & $\begin{array}{l}\text { CP } \\
L L\end{array}$ & $\begin{array}{l}\text { EC } \\
C T\end{array}$ & $\begin{array}{l}\text { PT } \\
S A\end{array}$ & $\begin{array}{l}\text { PD } \\
F O\end{array}$ & $\begin{array}{c}\mathrm{PC} \\
\text { SI }\end{array}$ \\
\hline $\begin{array}{l}\mathrm{PN} \\
B W\end{array}$ & & 0,46 & 0,29 & 0,36 & 0,35 & 0,31 & 0,02 & 0,07 & $-0,13$ & 0,30 & 0,12 & 0,06 & 0,02 & $-0,11$ & 0,08 \\
\hline $\begin{array}{l}\mathrm{P} 7 \\
W 7\end{array}$ & 0,01 & & 0,77 & 0,80 & 0,70 & 0,54 & $-0,17$ & 0,14 & 0,19 & 0,35 & 0,27 & 0,25 & 0,08 & $-0,25$ & 0,16 \\
\hline $\begin{array}{l}\mathrm{P} 12 \\
\text { W12 }\end{array}$ & 0,01 & 0,01 & & 0,81 & 0,75 & 0,68 & 0,03 & $-0,13$ & 0,32 & 0,55 & 0,46 & 0,23 & $-0,27$ & 0,07 & 0,33 \\
\hline $\begin{array}{l}\text { P18 } \\
\text { W18 }\end{array}$ & 0,01 & 0,01 & 0,01 & & 0,82 & 0,71 & 0,02 & 0,07 & 0,23 & 0,58 & 0,45 & 0,28 & $-0,31$ & 0,10 & 0,34 \\
\hline $\begin{array}{l}\text { PA } \\
\text { SW }\end{array}$ & 0,01 & 0,01 & 0,01 & 0,01 & & 0,89 & $-0,05$ & $-0,07$ & 0,30 & 0,66 & 0,52 & 0,48 & $-0,25$ & 0,01 & 0,35 \\
\hline $\begin{array}{l}\mathrm{PF} \\
C W\end{array}$ & 0,01 & 0,01 & 0,01 & 0,01 & 0,01 & & 0,40 & $-0,13$ & 0,38 & 0,60 & 0,50 & 0,37 & $-0,33$ & 0,14 & 0,34 \\
\hline $\begin{array}{l}\mathrm{RC} \\
D P\end{array}$ & NS* & NS & NS & 0,82 & NS & 0,01 & & $-0,16$ & 0,21 & 0,01 & 0,04 & $-0,14$ & $-0,20$ & 0,26 & 0,01 \\
\hline $\begin{array}{l}\text { MF } \\
P M\end{array}$ & NS & NS & NS & NS & NS & NS & NS & & $-0,10$ & $-0,05$ & $-0,32$ & $-0,10$ & 0,23 & $-0,18$ & $-0,14$ \\
\hline $\begin{array}{l}\text { EG } \\
F T\end{array}$ & NS & NS & 0,01 & 0,02 & 0,01 & 0,01 & 0,04 & NS & & 0,12 & 0,29 & 0,12 & $-0,23$ & $-0,03$ & 0,36 \\
\hline $\begin{array}{l}C C \\
C L\end{array}$ & 0,01 & 0,01 & 0,01 & 0,01 & 0,01 & 0,01 & NS & NS & NS & & 0,51 & 0,42 & $-0,33$ & 0,16 & 0,32 \\
\hline $\begin{array}{l}C P \\
L L\end{array}$ & NS & 0,03 & 0,01 & 0,01 & 0,01 & 0,01 & NS & 0,01 & 0,01 & 0,01 & & 0,33 & $-0,37$ & 0,21 & 0,33 \\
\hline $\begin{array}{l}\text { EC } \\
C T\end{array}$ & NS & 0,04 & 0,02 & 0,01 & 0,01 & 0,01 & NS & NS & NS & 0,01 & 0,01 & & $-0,11$ & $-0,03$ & 0,19 \\
\hline $\begin{array}{l}\mathrm{PT} \\
S P\end{array}$ & NS & NS & 0,01 & 0,01 & 0,01 & 0,01 & NS & 0,02 & 0,03 & 0,01 & 0,01 & NS & & $-0,73$ & $-0,67$ \\
\hline $\begin{array}{l}\text { PD } \\
F P\end{array}$ & NS & 0,05 & NS & 0,33 & NS & NS & 0,01 & NS & NS & NS & 0,04 & NS & 0,01 & & $-0,02$ \\
\hline $\begin{array}{l}\mathrm{PC} \\
\text { SiP }\end{array}$ & NS & NS & 0,01 & 0,01 & 0,01 & 0,01 & NS & NS & 0,01 & 0,01 & 0,01 & NS & 0,01 & NS & \\
\hline
\end{tabular}

* Diferença não significativa (not significant difference). 
desempenho até os sete meses, e deixa de existir se o bezerro for separado da mãe aos sete meses de idade $(r=0,01)$ com bom peso.

A correlação entre peso aos sete meses e espessura de gordura foi de $0,19(\mathrm{P}>0,05)$, mostrando que o ganho de peso após o desmame possui maior efeito sobre o grau de acabamento da carcaça do novilho. Herring (2003), ao comentar as correlações genéticas do crescimento pós-desmame (sete meses) com características de carcaça ajustadas para a idade dos animais, cita coeficiente de correlação de 0,21 entre o ganho de peso após o desmame e a espessura de gordura na carcaça. No presente trabalho, as correlações entre a espessura de gordura e as pesagens feitas após o desmame foram de 0,32; 0,23 e 0,30, respectivamente, para pesos aos 12 meses $(\mathrm{P}<0,01)$, aos 18 meses $(\mathrm{P}<0,05)$ e ao abate dos animais $(\mathrm{P}<0,01)$, enquanto o peso de carcaça apresentou $r=0,38 \mathrm{com}$ a espessura de gordura $(\mathrm{P}<0,01)$.

Em seu trabalho, Vaz et al. (2002) comentam que a produção de leite da vaca afeta significativamente o marmoreio da carne, mas não apresenta efeito sobre a espessura de gordura da carcaça ao abate (24 meses de idade), dados que ratificam os resultados apresentados anteriormente por Marshall (1987) e os publicados por Herring (2003), sendo que este último autor cita $r=0,07$ entre ganho de peso do desmame ao abate e a característica marmoreio da carne.

O comprimento de carcaça esteve positivamente correlacionado $(\mathrm{P}<0,01)$ com os pesos dos animais em diferentes idades $(0,30 ; 0,35 ; 0,55 ; 0,58$ e 0,66 , ao nascer, aos 7, 12, 18 meses e ao abate, respectivamente). Também foi observada correlação positiva $(\mathrm{P}<0,05)$ entre o comprimento de carcaça e a porcentagem de costilhar $(r=0,32)$ - resultado da medida a ser tomada desde o osso púbis até a porção média da primeira costela (Restle et al., 1999c, 2001; Vaz, 1999).

A maturidade fisiológica da carcaça não apresentou correlação significativa com os pesos de abate, de carcaça fria e rendimento de carcaça, estando correlacionada somente com o comprimento de perna ( $r=-0,32 ; \mathrm{P}<0,01)$ e a porcentagem de corte serrote $(r=0,23 ; P<0,05)$. Restle et al. (1999b) observaram que, quando os animais foram desmamados precocemente, a maturidade fisiológica apresentou coeficiente de correlação significativo com o comprimento de perna ( $r=-0,39)$, mas, quando o desmame ocorreu aos sete meses de idade, esse valor foi de apenas -0,04. Os autores citam também que, independentemente da idade de desmame a que os animais são submetidos, não existe correlação entre a maturidade e as características de desenvolvimento corporal avaliadas.

\section{Conclusões}

Novilhos Nelore que apresentaram ganho de peso diário abaixo de $0,44 \mathrm{~kg}$ por dia antes dos sete meses e maior que $0,44 \mathrm{~kg}$ dos sete meses ao abate não diferiram no peso ao abate e peso de carcaça de novilhos com desempenho inverso.

Os pesos aos 12 e 18 meses de idade foram afetados pelo ganho de peso antes dos sete meses de idade, ao passo que os pesos de abate e de carcaça fria, pelo ganho de peso antes e após os sete meses.

Os maiores ganhos de peso antes e após os sete meses de idade se refletem em maior porcentagem de costilhar e menor percentual de traseiro especial na carcaça.

Em novilhos Nelore, o ganho de peso antes dos sete meses de idade possui importante efeito nas características de desenvolvimento ponderal, durante a recria e terminação, e na deposição de gordura na carcaça.

Em novilhos Nelore, o peso ao nascer é positivamente correlacionado com as características de desenvolvimento ponderal e com o peso e comprimento de carcaça.

\section{Literatura Citada}

ABERLE, E.D.; REEVES, M.D.; JUDGE, R.E. et al. Palatability and muscle characteristics of cattle with controled weight gain: time on a high energy diet. Journal of Animal Science, v.52, n.4, p.757-763, 1981.

ARBoitTe, M.Z.; ReSTlE, J.; ALVES Filho, D.C. Desempenho em confinamento de novilhos 5/8 Nelore 3/8 Charolês abatidos em três estádios de desenvolvimento. Revista Brasileira de Zootecnia, v.33, n.4, p.947-958, 2004.

BAIL, C.A.T.; BRONDANI, I.L.; RESTLE, J. Níveis de concentrado na fase de terminação em confinamento para novilhos previamente mantidos em pastagem nativa ou cultivada. Ciência Rural, v.30, n.1, p.151-157, 2000.

BARBER, K.A.; WILSON, L.L.; ZIEGLER, J.H. et al. Charolais and Angus steers slaughtered at equal percentages of mature cow weight. I. Effects of slaughter weight and energy density on carcass traits. Journal of Animal Science, v.52, n.2, p.218-231, 1981.

BOWLING, R.A.; SMITH, G.C.; CARPENTER, Z.L. et al. Comparison of forage-finished and grain-finished beef carcasses. Journal of Animal Science, v.45, n.2, p.209-215, 1977.

CIESLAR, S.; FLEMING, J., Compensatory growth - an hypothesis (Chapter 8), 2003, < http:// www.aps.uoguelph.ca/ cantj/ans626ch8.pdf (14/04/2003).

COSTA, E.C.; RESTLE, J.; VAZ, F.N. et al. Características de carcaça de novilhos Red Angus superprecoces abatidos com diferentes pesos. Revista Brasileira de Zootecnia, v.31, n.1, p.119-128, 2002.

R. Bras. Zootec., v.33, n.4, p.1029-1038, 2004 
DI MARCO, O.N. Crecimiento y respuesta animal. Balcarce: Associación Argentina de Producción Animal, 1994. 129p.

HARRISON, A.R.; SMITH, M.E.; ALLEN, D.M. et al. Nutritional regime effects on quality and yield characteristics of beef. Journal of Animal Science, v.47, n.2, p.383-388, 1978.

HERRING, W. What have we learned about trait relationships? < http://www. animal.ufl.edu/extension/beef/ documents/short02/herring.pdf (18/01/2003).

HOGG, B.W. Compensatory growth in ruminants. In: PEARSON, A.M.; DUTSON, T.R. Growth regulation in farm animals: advances in meat research. New York: Elsevier Science Publishers Ltda, 1991. p.103-134.

HORNICK, J.L.; Van EENAEME, C.; CLINQUART, A. et al. Different periods of feed restriction before compensatory growth in Belgian Blue bulls: 1. Animal performance, nitrogen balance, meat characteristics, and fat composition. Journal of Animal Science, v.76, n.1, p.249-259, 1998.

LAWRENCE, T.L.J.; FOWLER, V.R. Growth of farm animals. London: British Library, 1997. 330p.

MARSHALL, T.T.; HARGROVE, D.D.; OLSON, T.A. Heterosis and additive breed effects on feedlot and carcass traits from crossing Angus and Brown Swiss. Journal of Animal Science, v.64, n.5, p.1332-1339, 1987.

MULLER, L. Normas para avaliação de carcaças e concurso de carcaça de novilhos. 2.ed. Santa Maria: Universidade Federal de Santa Maria, 1987. 31p.

MULLER, L.; PRIMO, A.T. Influência do regime alimentar no crescimento e terminação de bovinos e na qualidade da carcaça. Pesquisa Agropecuária Brasileira, v.21, n.4, p.445-452, 1986.

OLSON, L.W.; CUNDIFF, L.V.; GREGORY, K.E. Maternal heterosis effects on postweaning growth and carcass traits in beef cattle. Journal Animal Science, v.46, n.6, p.15521562, 1978.

PASCOAL, L.L.; RESTLE, J.; VAZ, F.N. et al. Efeito da idade e peso das bezerras e produção de leite da vaca sobre o desempenho de bezerras de corte desmamadas precocemente. In: REUNIÃO ANUAL DA SOCIEDADE BRASILEIRA DE ZOOTECNIA, 37., 2000, Viçosa, MG. Anais... Viçosa, MG: Sociedade Brasileira de Zootecnia, 2000. p.163.

RESTLE, J.; KEPLIN, L.A.S.; VAZ, F.N. et al. Características quantitativas da carcaça de novilhos Charolês abatidos com diferentes pesos. Pesquisa Agropecuária Brasileira, v.32, n.8, p.851-856, 1997.

RESTLE, J.; BRONDANI, I.L.; BERNARDES, R.A.C. O novilho superprecoce. In: RESTLE, J. (Ed.) Confinamento, pastagens e suplementação para produção de bovinos de corte. Santa Maria: Universidade Federal de Santa Maria, 1999a. p.191-214.

RESTLE, J.; CREDÓTES, L.; VAZ, F.N. et al. Características de carcaça e da carne de novilhas Charolês e 3/4 Charolês 1/4 Nelore, terminadas em confinamento. Revista Brasileira de Zootecnia, v.30, n.3 (Supl. 1), p.1065-1075, 2001.

RESTLE, J.; VAZ, F.N.; BRONDANI, I.L. et al. Estudo da carcaça de machos Braford desmamados aos 72 ou 210 dias, abatidos aos catorze meses. Pesquisa Agropecuária Brasileira, v.34, n.11, p.2137-2144, 1999b.
RESTLE, J.; VAZ, F.N.; PASCOAL, L.L. et al. Efeito do desmame precoce na carcaça de novilhos terminados em pastagem e abatidos aos 24 meses. Pesquisa Agropecuária Brasileira, v.34, n.11, p.2129-2136, 1999c.

RESTLE, J.; VAZ, F.N. Produção de carne com qualidade. In: RESTLE, J.; BRONDAIN, I.L.; PASCOAL, L.L. et al. (Eds.) Produção intensiva com qualidade em bovinos de corte. Santa Maria: Universidade Federal de Santa Maria, 1998. p.104-119.

RESTLE, J.; VAZ, F.N. Tendências de mercado e entraves tecnológicos para a cadeia produtiva da carne bovina. In: MELLO, N.A.; ASSMANN, T.S. (Eds.) Encontro de integração lavoura-pecuária no sul do Brasil. CEFET/ IAPAR, 2002. p.167-188.

THIAGO, L.R.L.S.; SILVA, J.M.; FEIJÓ, G.L.D. et al. Efeito da restrição alimentar no desempenho e características de carcaça de bovinos confinados. In: REUNIÃO ANUAL DA SOCIEDADE BRASILEIRA DE ZOOTECNIA, 35., 1998, Botucatu. Anais... Botucatu: Sociedade Brasileira de Zootecnia, 1998, p.350-352.

TRENKLE, A.; DeWITT, D.L.; TOPEL, D.G. Influence of age, nutrition and genotype on carcass traits and cellular development of the $\mathrm{m}$. longissimus of cattle. Journal of Animal Science, v.46, n.6, p.1597-1603, 1978.

VAZ, F.N. Cruzamento alternado das raças Charolês e Nelore: características de carcaça e da carne de novilhos abatidos aos dois anos. Santa Maria: Universidade Federal de Santa Maria, 1999. 58p. Dissertação (Mestrado em Zootecnia) - Universidade Federal de Santa Maria, 1999.

VAZ, F.N.; RESTLE, J.; ALVES FILHO, D.C. et al. Características de carcaça e da carne de novilhos filhos de vacas $1 / 2$ Nelore 1/2 Charolês e 1/2 Charolês 1/2 Nelore acasaladas com touros Charolês ou Nelore. Revista Brasileira de Zootecnia, v.31, n.4, p.1734-1743, 2002.

VAZ, F.N.; RESTLE, J. Ganho de peso antes e após os sete meses no desenvolvimento e características quantitativas da carcaça novilhos Charolês abatidos aos dois anos. Revista Brasileira de Zootecnia, v.32, n.3, p.699-708, 2003.

VAZ, F.N.; ROSO, C.; VAZ, R.Z. Gerenciamento visando e eficiência econômica da pecuária de corte. In: RESTLE, J. (Ed.) Confinamento, pastagens e suplementação para produção de bovinos de corte, Santa Maria: Universidade Federal de Santa Maria, 1999. p.232-258.

VAZ, F.N.; VAZ, R.Z.; ROSO, C. Aplicação e gerenciamento de tecnologias na pecuária de corte moderna. In: RESTLE, J. (Ed.)Eficiência na produção de bovinos de corte. Santa Maria: Universidade Federal de Santa Maria, 2000. p.333-368.

YAMBAYAMBA, E.S.K.; PRICE, M.A.; FOXCROFT, G.R. Hormonal status, metabolic changes, and resting metabolic rate in beef heifers undergoing compensatory growth. Journal of Animal Science, v.74, n.1, p.57-69, 1996. 